\title{
CORRELATION BETWEEN LEPTIN, INSULIN AND POLYCYSTIC OVARY SYNDROME
}

\author{
By
}

\author{
Ashraf Fathy Mohamed, Abd El-Moneim Mohamed Zakaria, Makki \\ Abd El-Moneim Ali* and Ahmed Osama Abd El-Motaal
}

Departments of Obstetrics and Gynecology and Clinical Pathology*, Faculty of Medicine, Al-Azhar University

Corresponding author: Ashraf Fathy Mohamed, E-mail: ashraffathy9293@gmail.com

\begin{abstract}
Background: Polycystic ovary syndrome (PCOS), a heterogeneous, complex genetic trait of unclear etiology, is an important cause of ovulatory and menstrual irregularity, subfertility and infertility, clinically evident hyperandrogenism, and metabolic dysfunction in women. It is recognized as one of the most common endocrine/metabolic disorders of women.

Objective: To investigate the serum levels of insulin and leptin in and their correlation with the endocrine and metabolic peculiarities of PCOS.

Patients and methods: This study was carried out on 100 females attending the outpatient clinic of Al Azhar University Hospital seeking conception assistance during the period between April 2019 and august 2020. All women were in the reproductive age group, had primary infertility and diagnosed as having PCOS according to Rotterdam criteria. All patients included within this study were classified under two equal groups: Patient group included women having PCOS, and control group include normal fertile healthy women received no hormonal medication during the last 3 months preceding the study.

Results: The biochemical laboratory investigation, including follicle stimulating hormone (FSH) and luteinizing hormone (LH) showed no statistically significant difference between control and patient groups. In contrast, the serum levels of LH/ FSH, free testosterone, fasting insulin and leptin in the patient group showed a significant increase as compared with the control group. Serum leptin level was found to be significantly elevated in overweight and obese patients. No significant differences in serum leptin were noted in normal weight patients. Similarly, serum insulin level was significantly higher in overweight and obese patients compared to overweight and obese control group. The serum leptin levels were plotted against Body mass index (BMI) in both control and patient group, significant correlations were observed. Also, there was a significant positive correlation between serum leptin and serum insulin levels.
\end{abstract}

Conclusion: Women with PCOS have altered leptin and insulin levels which were distinct differences between ovulating and non-ovulating women with PCOS. Also, there were significant differences in the levels of serum leptin levels and insulin levels between normal and overweight/obese women with PCOS.

Keywords: Leptin, Insulin, BMI, Polycystic Ovary Syndrome.

\section{INTRODUCTION}

Polycystic ovary syndrome (PCOS) is the most common endocrine disorder in women with a prevalence between 6 and $10 \%$ based on the National Institute of Health criteria and as high as $15 \%$ when the broader Rotterdam criteria are applied (Amsterdam ESHRE/ASRM, 2012); It is characterized by a clustering of hyperandrogenism (either clinical or biochemical), chronic anovulation, and polycystic ovaries, and it is frequently associated with insulin resistance (IR) and 
obesity. Polycystic ovary syndrome is also considered as a form of metabolic syndrome, frequently exhibiting central obesity, glucose intolerance or insulin resistance, atherogenic dyslipidemia, hypertension, increased low-density lipoprotein, and decreased high-density lipoprotein, a cluster of factors to predict a greater risk of future cardiovascular events and type 2 diabetes. However, up to date, the exact etiology of PCOS has not been fully understood (Tan et al., 2016).

Insulin can stimulate ovarian androgen production in normal women and in women with PCOS. However, ovarian cells of women with PCOS display a higher responsiveness for insulin stimulated androgen synthesis in vitro. Non obese and normoinsulinemic women with PCOS significantly improve their serum testosterone levels after serum insulin levels are reduced. It is therefore, probable that women develop PCOS because of a hypersensitivity of their intra ovarian insulin androgen signaling pathway. The characterization of this potential defect could have significant implications for the development of specific and more efficient treatments of PCOS (Adam et al., 2016).

Leptin is a product of the ob gene that acts as a sensor to the hypothalamus about the adipose tissue stores as well as a regulator of food intake and the energy balance. A positive relationship between leptin and fat mass and BMI has been reported. Several studies suggested that leptin may be involved in the reproductive axis function at both central and peripheral levels. Amenorrheic athletes have inadequate or low body fat and leptin. Leptin administration in women with hypothalamic amenorrhea improves the reproduction (Teede et al., 2019). Leptin affects the hypothalamic secretion of $\mathrm{GnRH}$ and gonadotropin secretion. High leptin may interfere with the development of the mature oocyte and may directly activate ovarian 17- $\alpha$ hydroxylase enzyme that is involved in ovarian and adrenal steroidogenesis (Sфrensen et al., 2019).

Leptin in the circulation is present in two main forms: a protein bound and a free form that is the biological active form. The soluble leptin receptor (sOB-R) circulates in human plasma and is accomplished by binding to leptin and symbolizes the significant leptin binding activity in humans (Fauser et al., 2012). In lean subjects, leptin circulates principally in the bound form while in obesity the leptin circulates mainly as a free form due to small sOB-R concentrations (Shele et al., 2020). The fraction of the total leptin concentrations to the sOB-R designates the free leptin index (FLI). The role of sOB-R in the reproductive system especially in PCOS is still uncertain. Few studies addressed the potential role of SOB-R in PCOS that showed inconsistent results (Tan et al., 2016). In addition, conflicting results have been described on circulating leptin levels among women with different BMI (lean, overweight, and obese women) with PCOS.

The aim of this work was to investigate the serum levels of insulin and leptin in and their correlation with the endocrine and metabolic peculiarities of PCOS. 


\section{PATIENTS AND METHODS}

This study was carried out on 100 females attending the Outpatient clinic of Al Azhar University Hospital seeking conception assistance. They were informed about the aim of the work and a written consent was taken from them. All women were in the reproductive age group, had primary infertility, and diagnosed as having PCOS according to Rotterdam criteria.

\section{Inclusion criteria:}

1. All women in the reproductive age (20 -35 years old).

2. Having PCOS according to Rotterdam criteria (PCOS is a syndrome of ovarian dysfunction. Its cardinal features are hyperandrogenism and polycystic ovary morphology. Its clinical manifestations may include menstrual irregularities, signs of androgen excess, and obesity.

\section{Exclusion criteria:}

1. Age over 35 years old.

2. Receiving medicaments for any other diseases.

3. Women who had induction of ovulation or hormonal treatment in last three months

4. Evidence of systemic diseases (Cushing syndrome, congenital adrenal hyperplasia, acromegaly, hypothalamic disorders, hyperprolactinemia and systemic inflammatory diseases)

5. Women with other causes of hirsutism and oligomenorrhea.

Patients included within this study were classified under two equal groups:
Patient group included women having PCOS, and Control group included normal fertile healthy women received no hormonal medication during the last 3 months preceding the study.

All women included within this study were subjected to history taking, clinical examination, assessment of body mass index (BMI) and ultrasonographic examination. A total volume of $5 \mathrm{ml}$ of the venous blood was taken from each case in the morning of the 3rdday throughout the cyclefrom subjects with regular cycles and collected independently from the day of menses from subjects with menstrual irregularity to measure fasting serum concentrations of leptin, insulin, follicular stimulating hormone, luteinizing hormone and free testosterone.

Subjects came into the lab after 10 hours fast, with the exception of water. Weight and height for each subject were measured and BMI was calculated as $\mathrm{kg} / \mathrm{m} 2$. Five $\mathrm{ml}$ of blood was withdrawn and allowed to clot for at least 30 minutes, and centrifuged at $4000 \mathrm{rpm}$ for 20 minutes. The serum was then aliquoted at $-20^{\circ} \mathrm{C}$ until needed for analysis.

The measurement of hormones was done via a quantitative sandwich ELISA (enzyme linked immunoabsorbant assay) (Voller et al., 1978).

Serum leptin concentrations were measured using an enzyme linked immunoabsorbant assay (MYBIOSOURCE). The intra-assay CVs had a mean of less than $15 \%$. The minimum detectableconcentration was 0.1 $\mathrm{ng} / \mathrm{ml}$. Expected normal concentrations for serum leptin are between $0.625-20$ $\mathrm{ng} / \mathrm{ml}$. 
Serum insulin concentrations were measured using an enzyme linked immunoabsorbant assay (Alpco Diagnostic). The intra-assay CVs had a mean of $10.6 \%$. The minimum detectable concentration was $3 \mu \mathrm{IU} / \mathrm{ml}$. Expected normal concentrations of insulin are between $5-20 \mu \mathrm{IU} / \mathrm{ml}$.All ELISA plates were read with Stat Fax 4200 spectrophotometer.

Estimations of serum levels of FSH and LH were performed by radio-immunoassays. Serum concentrations of leptin, insulin, FSH, LH and testosterone were measured in the morning fasting, of all cases.
Patients' data were presented as frequency and percentage for categorical variables, mean and SD for numerical variables. Groups were compared by independent samples Student t-test or Mann-Whitney U test, and X2-test for numerical and categorical data, respectively. All data and statistical analyses were handled by statistical package for the social sciences (SPSS, IBM, SPSS Inc. Chicago, USA) computer package version 18 . $\mathrm{P}$ value $\leq 0.05$ was considered significant. Correlations were tested.

\section{Statistical Analysis:}

\section{RESULTS}

The age in years in control group was $27.4 \pm$ 3.9. Patient group had no significant change age $24.7 \pm 3.5$ than the control group $(\mathrm{P}>0.05)$. In this study, significant differences $(\mathrm{P}<0.05)$ were detected with respect to BMI, number of regular cycle pattern, oligomenorrhea and amenorrhea in addition to absence of hirsutism (Table 1).

Table (1): Clinical data of studied groups

\begin{tabular}{|c|c|c|c|}
\hline Parameters $\quad$ Groups & $\begin{array}{c}\text { Patient's } \\
\text { group } \\
(n=50)\end{array}$ & $\begin{array}{c}\text { Control } \\
\text { group } \\
(n=\mathbf{5 0})\end{array}$ & $P$ value \\
\hline Age (years) $)_{\text {Mean }(\mathrm{SD})}$ & $24.7(3.5)$ & $27.4(3.9)$ & $<\mathbf{0 . 0 0 1}$ \\
\hline BMI $\left(\mathbf{k g} / \mathbf{m}^{2}\right)_{\text {Mean (SD) }}$ & $31.9(3.7)$ & $25.5(2.3)$ & $<0.001$ \\
\hline Infertility duration (years) Mean (SD) & $3.4(1.2)$ & - & \\
\hline Regular Cycle pattern ${ }_{\mathrm{No}(\%)}$ & $18(36 \%)$ & $46(92 \%)$ & 0.001 \\
\hline 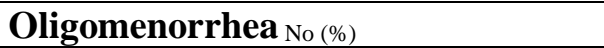 & $29(58 \%)$ & $3(6 \%)$ & 0.001 \\
\hline Amenorrhea $\mathrm{No}_{(\%)}$ & $3(6 \%)$ & $1(2 \%)$ & $<0.05$ \\
\hline $\begin{array}{l}\text { Hirsutism }_{\text {No }(\%)} \\
\text { No } \\
\text { Mild } \\
\text { Moderate or Severe }\end{array}$ & $\begin{array}{l}27(54 \%) \\
13(26 \%) \\
10(20 \%)\end{array}$ & $\begin{array}{c}50(100 \%) \\
0(0 \%) \\
0(0 \%)\end{array}$ & 0.001 \\
\hline
\end{tabular}

The biochemical laboratory investigation, including FSH and $\mathrm{LH}$ showed no statistically significant difference between control and patient groups $(\mathrm{P}>0.05)$ as shown in Table 2. In contrast, the serum levels of LH/ FSH, free testosterone, fasting insulin and leptin in the patient group showed a significant increase $(\mathrm{P}<0.05)$ as compared with the control group (Table 2). 
Table (2): Laboratory investigation of studied groups

\begin{tabular}{|l|c|c|c|}
\hline \multirow{2}{*}{ Groups } & $\begin{array}{c}\text { Patient's group } \\
(\mathbf{n}=\mathbf{5 0})\end{array}$ & $\begin{array}{c}\text { Control group } \\
(\mathbf{n}=\mathbf{5 0})\end{array}$ & \multirow{2}{*}{ P value } \\
\cline { 2 - 3 } Parameters & Mean $(\mathbf{S D})$ & Mean $(\mathbf{S D})$ & \\
\hline FSH $(\mathbf{m I U} / \mathbf{m l})$ & $4.1(1.4)$ & $5.3(1.4)$ & 0.358 \\
\hline LH $(\mathbf{m I U} / \mathbf{m l})$ & $7.7(1.6)$ & $6.5(2.5)$ & 0.153 \\
\hline LH:FSH ratio & $1.8(0.8)$ & $1.2(0.3)$ & $\mathbf{0 . 0 2 7}$ \\
\hline Free testosterone $(\mathbf{p g} / \mathbf{m l})$ & $1.7(0.7)$ & $1.2(0.5)$ & $\mathbf{0 . 0 4 1}$ \\
\hline Fasting Insulin $(\boldsymbol{\mu l U} / \mathbf{m l})$ & $16.8(3.9)$ & $9.4(3.2)$ & $\mathbf{0 . 0 3 8}$ \\
\hline Leptin $(\mathbf{n g} / \mathbf{m l})$ & $38.5(5.3)$ & $20.2(3.6)$ & $<\mathbf{0 . 0 0 1}$ \\
\hline
\end{tabular}

Serum leptin level was found to be significantly elevated $(\mathrm{P}<0.05) \quad$ in overweight and obese patients. No significant differences in seum leptin were noted in normal weight patients.
Similarly, serum insulin level was significantly higher in overweight and obese patients compared to overweight and obese control group (Table 3).

Table (3): Serum leptin level and serum insulin level according to BMI categories in studied groups

\begin{tabular}{|l|c|c|c|}
\hline \multirow{2}{*}{ Garameters } & $\begin{array}{c}\text { Patient's group } \\
(\mathbf{n = 5 0})\end{array}$ & $\begin{array}{c}\text { Control group } \\
(\mathbf{n = 5 0})\end{array}$ & \multirow{2}{*}{ P value } \\
\cline { 2 - 3 } & Mean (SD) & Mean (SD) & \\
\hline Serum leptin & $23.3(4.6)$ & $19.2(2.8)$ & $<\mathbf{0 . 0 0 1}$ \\
\hline Normal (<25) & $28.4(5.2)$ & $20.4(4.1)$ & $<\mathbf{0 . 0 0 1}$ \\
\hline Overweight (25-30) & $36.7(7.6)$ & $27.5(5.5)$ & $\mathbf{0 . 0 0 1}$ \\
\hline Obese (>30) & $12.1(3.5)$ & $9.2(2.4)$ & 0.417 \\
\hline Serum insulin & $18.3(4.2)$ & $11.2(3.8)$ & $\mathbf{0 . 0 3 1}$ \\
\hline Normal $(<25)$ & $22.1(5.6)$ & $15.6(4.2)$ & $\mathbf{0 . 0 1 7}$ \\
\hline Overweight $(\mathbf{2 5 - 3 0 )}$ & \multicolumn{3}{|c}{} \\
\hline Obese (>30) &
\end{tabular}

The serum leptin levels were plotted against BMI in both control and patient group, significant correlations were observed $(\mathrm{P}<0.05)$. Also, there was a significant positive correlation between serum leptin and serum insulin levels (Table 4).

Table (4): Correlation between (BMI and serum leptin level), (BMI and serum insulin level) and (serum leptin and serum insulin levels)

\begin{tabular}{|l|c|c|c|c|}
\hline \multirow{2}{*}{ Groups } & \multicolumn{2}{c|}{$\begin{array}{c}\text { Patient's group } \\
(\mathbf{n = 5 0})\end{array}$} & \multicolumn{2}{c|}{$\begin{array}{c}\text { Control group } \\
(\mathbf{n = 5 0})\end{array}$} \\
\cline { 2 - 5 } Parameters & $\mathbf{r}$ & $\mathbf{P}$ value & $\mathbf{R}$ & P value \\
\hline Leptin and BMI & 0.817 & $<\mathbf{0 . 0 0 1}$ & 0.485 & $\mathbf{0 . 0 0 7}$ \\
\hline Insulin and BMI & 0.993 & $\mathbf{0 . 0 3 8}$ & 0.163 & 0.388 \\
\hline Leptin and Insulin & 1.428 & $\mathbf{0 . 0 1 5}$ & 0.080 & 0.673 \\
\hline
\end{tabular}

Spearman correlations test 


\section{DISCUSSION}

Patient group had no significant change in age than the control group. In this study, significant differences $(\mathrm{P}<0.05)$ were detected with respect to BMI, number of regular cycle pattern, oligomenorrhea and amenorrhea in addition to absence of hirsutism. This makes the study more relevant to specify the general PCOS characteristics in the patient group. The mean duration of infertility (in the PCOS group) ensured a homogenous group of PCOS from general population.

In the present investigation, the biochemical laboratory investigation, including $\mathrm{FSH}$ and $\mathrm{LH}$ showed no statistically significant difference between control and patient groups. In contrast, the serum levels of LH/ FSH, free testosterone, fasting insulin and leptin in the patient group showed a significant increase as compared with the control group. This was supported in research as a significant difference in insulin levels in women with PCOS was found (Liu et al., 2019). Our findings agreed with those who found significant higher fasting insulin in women with PCOS than normal controls (Rasool et al., 2019). On the contrary, our present work did not agree with other researchers who found a non-significant difference between PCOS patients and control group in regard to serum insulin (Beyazit et al., 2020) although it was higher among the PCOS group, this can be explained by the fact that most of their studied PCOS women were not obese.

Women with PCOS were hyperandrogenic and most of them were obese. The impact of obesity was usually considered to operate through the associated insulin resistance. It has become apparent that insulin resistance and hyperinsulinemia play a critical role in PCOS pathogenesis. Numerous studies have demonstrated that any treatment aimed at improving insulin resistance in women with PCOS results in lower androgen levels and improves ovulatory function. Yet, this hypothesis was supported by other results, concerned with a normalizing insulin level in treating PCOS patients (García-Beltran et al., 2020).

Also, our results revealed in accordance with several studies that women with PCOS exhibit abnormal adipocytokine concentrations in the form of increased serum leptin levels compared to weight matched controls (Mitkova, 2020 and Polak et al., 2020).

This may be due to a marked disruption in the serum levels of adipokines occurs in women with PCOS. Specifically, increases in leptin have been reported in different studies. The role of adipokines and their receptors in the development of hyperandrogenism in PCOS is well established. This may be due to the ability of leptin to cause a significant increase in the androstenedione level by affecting expression of key steroidogenic enzymes. Based on the results presented herein, PCOS group has significant elevated leptin levels and testosterone levels in comparison with control group.

Serum leptin was found to be significantly elevated in overweight and obese patients when compared to control 
group with matching BMI. This was supported by previous studies where serum leptin concentrations in women with obese PCOS have been reported to be higher than control (Polak et al., 2020). On the contrary, leptin mean value was not different in PCOS patients compared with the normal controls (Baldani et al., 2019). Also, PCOS is not a consequence of mutations of the leptin or leptin receptor genes (Polak et al., 2020).

Moreover, other studies have shown that BMI influences the level of leptin regardless of PCOS status (Sayed et al., 2019). A possible explanation for this discrepancy is that there are several different phenotypes of PCOS that exist. A study verified the need to differentiate between ovulatory and anovulatory women with PCOS due to differences in various blood parameters, including adipocytokine release (Barber et al., 2019).

In the present study, there was a positive correlation between BMI and serum fasting insulin studied groups. Furthermore, when the serum leptin levels were plotted against BMI in both control and patient group, significant correlations were observed with a more positive correlation in PCOS.

In agreement with other studies, these results supported the previously published data demonstrating a positive correlation between serum leptin levels and BMI in normal and in women with PCOS (Athrey et al., 2019 and Aversa et al., 2020).

The explanation of our results concerning leptin may be due to the fact that leptin was regulated by fat mass such that leptin increases with an increase in fat mass. This suggested that adipocytokine secretion was altered in overweight women with PCOS, or that BMI was such an important part of adipocytokine concentrations.

It has been established that there is a positive relationship between leptin and fat mass in women with and without PCOS (Chen et al., 2015). In this study, leptin was significantly higher in the overweight-obese group compared to the normal group. These values are concordant with previous research that found higher leptin levels in overweight/obese subjects with PCOS compared to normal subjects with PCOS.

In addition, when all of the subjects were studied as a whole, BMI was positively correlated with leptin.

The significant elevation of leptin in the overweight and obese PCOS groups may be due to the fact that their fat mass is higher compared to the other groups, causing more abnormal adipocytokine release which would have more than an effect on other parameters (Pehlivanov \& Mitkov, 2010 and Jalilian et al., 2016).

However, the hypothesis that variations in the leptin receptor gene locus affect insulin regulation was stated by Okasanen et al, it was supported by our study (Oksanen et al., 2010).

Our significant positive correlation that was detected between serum insulin and leptin levels agrees with that stated by Bloomgarden who found that insulin acutely increases plasma leptin, suggesting a role of hyperinsulinemia in insulin resistance, which is associated to an increase in adipocyte inflammatory factors (Bloomgarden, 2010). 
There are several different hypotheses regarding the etiology of PCOS, but the most popular one is that hyperinsulinemia causes the pituitary and adrenal glands to hypersecrete testosterone, leading to hyperandrogenemia and many of the symptoms of PCOS such as anovulation (Zeng et al., 2020).

Showing that even though fat mass influences leptin levels, insulin is probably involved in determining these levels as well. Insulin seems to have a stronger relationship with leptin than BMI does (Rashid et al., 2020).

This was supported also by Bungau et al. (2020) who stated that leptin showed a significant positive correlation to insulin. Since insulin increases leptin levels.

Since the etiology of PCOS may depend on increased levels of insulin. Furthermore, insulin increases levels of leptin (Shang et al., 2020).

\section{CONCLUSION}

Women with PCOS have altered leptin and insulin levels which were distinct differences between ovulating and nonovulating women with PCOS. Also, there were significant differences in the levels of serum leptin levels and insulin levels between normal and overweight/obese women with PCOS. Furthermore, the correlations of leptin, insulin measured with BMI was significant.

\section{REFERENCES}

1. Adam BH, Morley L, Misso M, Franks S, Legro $R$ and Teede H. (2016): The Management of Anovulatory Infertility in Women with Polycystic Ovary Syndrome: An Analysis of the Evidence to Support the Development of Global WHO
Guidance. Human Reproduction Update, 22 (6): 687-708.

2. Amsterdam ESHRE/ASRM-Sponsored $3^{\text {rd }}$ PCOS Consensus Workshop Group (2012): Consensus on women's health aspects of poly-cystic ovary syndrome (PCOS). Hum Reprod., 27(1):14-24.

3. Athrey M, Manjulata $K$ and Sameer $A$ (2019): To Evaluate the Association between Serum Leptin and Insulin/Insulin Resistance in Polycystic Ovarian Syndrome in a Tertiary Care Centre in North India. Asian Journal of Biochemistry, Genetics and Molecular Biology, 19: 1-8.

4. Aversa A, Sandro LV, Rocco R, Gambineri A and Alberto F. (2020): Fundamental Concepts and Novel Aspects of Polycystic Ovarian Syndrome: Expert Consensus Resolutions. Frontiers in Endocrinology, 11: 1-15.

5. Baldani D, Skrgatic L, Kasum M, Zlopasa G, Oguic S and Herman $M$. (2019): Altered Leptin, Adiponectin, Resistin and Ghrelin Secretion May Represent an Intrinsic Polycystic Ovary Syndrome Abnormality. Gynecological Endocrinology, 35 (5): 401-5.

6. Barber TM, Petra H, Martin OW and Stephen F. (2019): Obesity and Polycystic Ovary Syndrome: Implications for Pathogenesis and Novel Management Strategies. Clinical Medicine Insights: Reproductive Health, 13: 1179-88.

7. Beyazit F, Fatih K, Pek E and Beyazit Y. (2020): Association of Serum Midkine Levels with Insulin Resistance and Obesity in Patients with Polycystic Ovarian Syndrome. Libyan Journal of Medical Sciences, 4 (3): 120-28.

8. Bloomgarden ZT. (2010): Second World Congress on the Insulin Resistance Syndrome: Mediators, Pediatric Insulin Resistance, the Polycystic Ovary 
Syndrome, and Malignancy. Diabetes Care, 28:1821-30.

9. Bungau S, Tapan B, Delia T, Florin B, Ovidiu B, Camelia D and Cosmin V. (2020): "Interactions between Leptin and Insulin Resistance in Patients with Prediabetes, with and without NAFLD. Experimental and Therapeutic Medicine, 20(6): 1-1.

10. Chen CI, Ming IH, Shyh HL, Yuan CI, Chun SH and Chii RT. (2015): Adiponectin and Leptin in Overweight/Obese and Lean Women with Polycystic Ovary Syndrome. Gynecological Endocrinology, 31 (4): 264-68.

11. Chou SH, John PC, Xiaowen L, Giuseppe M, Chuanyun G, Rianna S and Mantzoros C. (2011): Leptin Is an Effective Treatment for Hypothalamic Amenorrhea. PNAS, 108 (16): 6585-90.

12. Fauser CJM, Basil CT, Robert WR, Richard SL, Adam BH, Roger L and Enrico C. (2012): Consensus on Women's Health Aspects of Polycystic Ovary Syndrome (PCOS). The Amsterdam ESHRE/ASRM-Sponsored 3rd PCOS Consensus Workshop Group. Fertility and Sterility, 97: 24-36.

13. García-Beltran C, Ruben $C$, Tania $Q$, Malpique $\mathrm{R}$, López-Bermejo $\mathrm{A}$ and Villarroya F. (2020): Reduced Circulating Levels of Chemokine CXCL14 in Adolescent Girls with Polycystic Ovary Syndrome: Normalization after Insulin Sensitization. BMJ Open Diabetes Research and Care, 8(1): 1035-42.

14. Jalilian N, Haghnazari $L$ and Rasolinia S. (2016): Leptin and Body Mass Index in Polycystic Ovary Syndrome. Indian Journal of Endocrinology and Metabolism, 20 (3): 324-28.
15. Liu RB, Yi L, Li QL, Wei X, Cheng G and Jian XY. (2019): Effects of Metformin Treatment on Soluble Leptin Receptor Levels in Women with Polycystic Ovary Syndrome. Current Medical Science, 39 (4): 609-14.

16. Mitkova OM. (2020): Clinical Impact of Insulin Resistance in Women with Polycystic Ovary Syndrome. In Polycystic Ovarian Syndrome. Intech Open, 12: 3239.

17. Oksanen L, Tiitinen A, Kaprio J, Koistinen HA, Karonen SL and Kontula K. (2010): "No Evidence for Mutations of the Leptin or Leptin Receptor Genes in Women with Polycystic Ovary Syndrome. Molecular Human Reproduction, 6 (10): 873-76.

18. Pehlivanov B and Mitkov M. (2010): Serum Leptin Levels Correlate with Clinical and Biochemical Indices of Insulin Resistance in Women with Polycystic Ovary Syndrome. European Journal of Contraception and Reproductive Health Care, 14 (2): 15359.

19. Polak AM, Krentowska A, Lebkowska A, Buczyńska $A$ and Adamska A. (2020): The Association of Serum Levels of Leptin and Ghrelin with the Dietary Fat Content in Non-Obese Women with Polycystic Ovary Syndrome. Nutrients, 12 (9): 2753-59.

20. Rashid A, Ganie M, Wani I, Bhat G, Shaheen F, Wani I, Shrivastava $M$ and Shah Z. (2020): Differential Impact of Insulin Sensitizers VsAnti-Androgen on Serum Leptin Levels in Vitamin D Replete PCOS Women: A Six Month Open Labeled Randomized Study. Hormone and Metabolic Research, 52 (2): 89-94.

21. Rasool SA, Ashraf S, Nabi M, Rashid F, Fazili K and Amin S. (2019): Elevated Fasting Insulin Is Associated with 
Cardiovascular and Metabolic Risk in Women with Polycystic Ovary Syndrome. Diabetes and Metabolic Syndrome: Clinical Research and Reviews, 13 (3): 2098-2105.

22. Sayed AA, Idris OF, Salah IA, Emadhamza AH and Bakhiet OA (2019): Assessment of Anti-Mullerian Hormone, Fertility Hormones (LH, TSH, Prolactin and Testosterone) and Leptin Hormone Among Obese with Poly Cystic Ovary Syndrome. SUST Repository, 20: 8-13.

23. Shang $Y$, Zhou $\mathrm{H}$, Hu $M$ and Feng $H$. (2020): Effect of Diet on Insulin Resistance in Polycystic Ovary Syndrome. Journal of Clinical Endocrinology and Metabolism. 105 (10): $1-15$.

24. Shele G, Jessica G and Speelman D. (2020): A Systematic Review of the Effects of Exercise on Hormones in Women with Polycystic Ovary Syndrome. Journal of Functional Morphology and Kinesiology, 5 (2): 35-42.

25. Sørensen AE, Pernille BU, Grzegorz M, Geiger J, Saliani N, Januszewski A and Jiang (2019): Hyperandrogenism and Metabolic Syndrome Are Associated
With Changes in Serum-Derived MicroRNAs in Women With Polycystic Ovary Syndrome. Frontiers in Medicine, 6: 242-46.

26. Tan $X$, Shengbing $L$, Ying $C$, Chao $F$, Hua L, Zhang $X$ and Wang Y. (2016): Effect of Metformin Treatment during Pregnancy on Women with PCOS: A Systematic Review and Meta-Analysis. Clinical and Investigative Medicine, 39 (4): 120-31.

27. Teede HJ, Misso ML, Costello MF, Dokras A, Laven J, Moran L, Piltonen $T$ and Norman R. (2019): Erratum. Recommendations from the International Evidence-Based Guideline for the Assessment and Management of Polycystic Ovary Syndrome. Human Reproduction, 34 (2): 388-388.

28. Voller A, Bartlett A and Bidwell DE (1978): Enzyme immunoassays with special reference to ELISA techniques. J Clin Path., 31:507-520.

29. Zeng $X$, Yuan $X$, Ya $L$, Shuang $L$ and Zhong M. (2020): Polycystic Ovarian Syndrome: Correlation between Hyperandrogenism, Insulin Resistance and Obesity. Clin Chim Acta., 502:214221. 


\section{العلاقه بين هرموز اللبتين والانسوليز و متلازمة تكيس المبايض}

أشرف فتحى محمد، عبد المنعم محمد زكريا، مكى عبد المنعم على*، أحمد أسامة عبد المثعال

قسمي التوليد وأمراض النساء و الباثولوجيا الأكلينيكية* ، كلية الطب، جامعة الأزهر

E-mail: ashraffathy9293@gmail.com

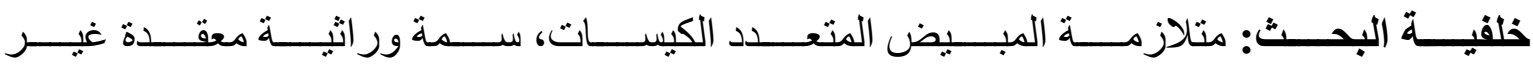

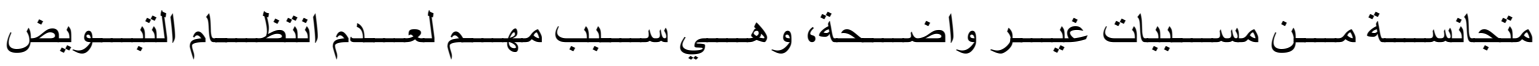

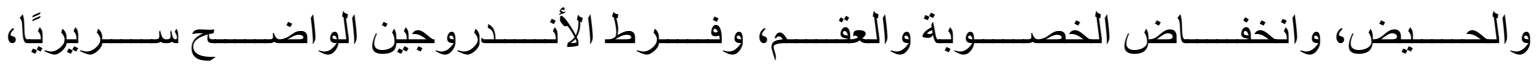

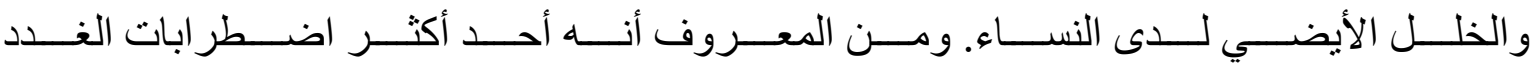
الصماء/ التمثيل الغذائي شيوعًا عند النساء.

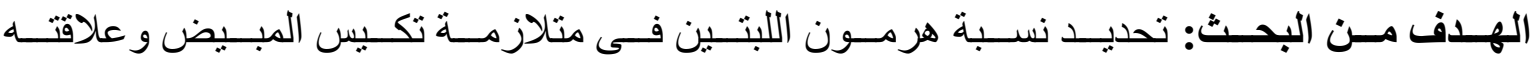
بالسمنة وهرمون الانسولين.

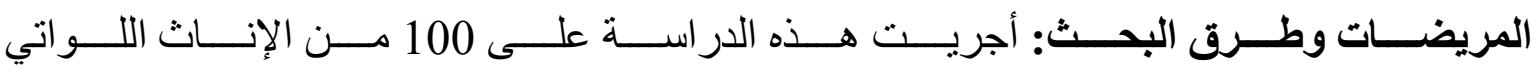

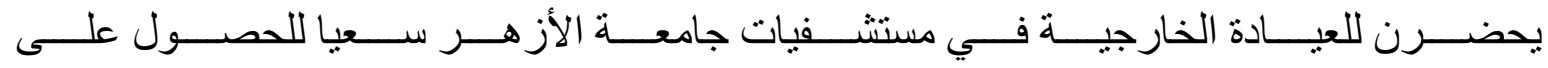

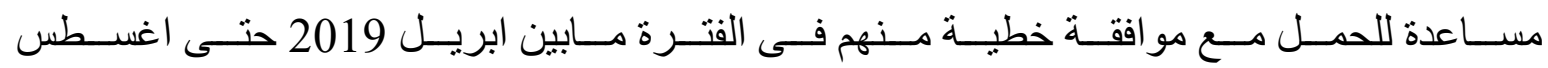

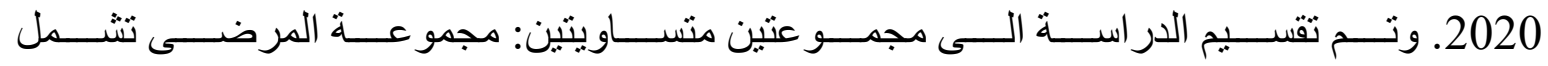

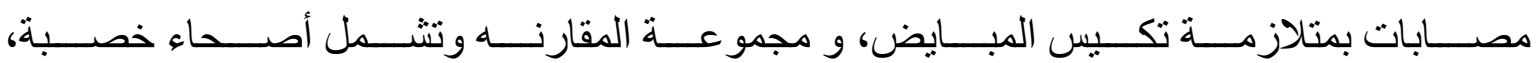
لم يتلقو ا أي دو اء هرموني خلال الأشهر الثلاثة الماضية السابقة للار اسة.

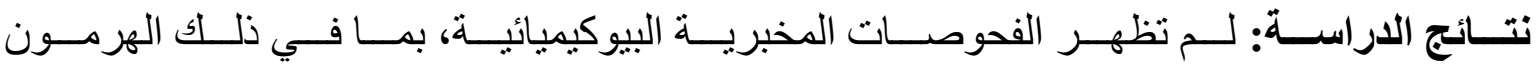

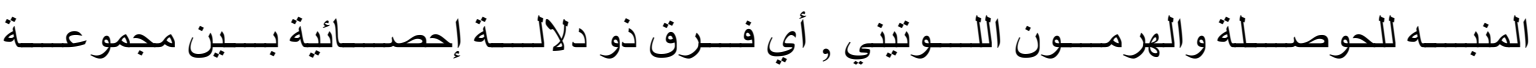

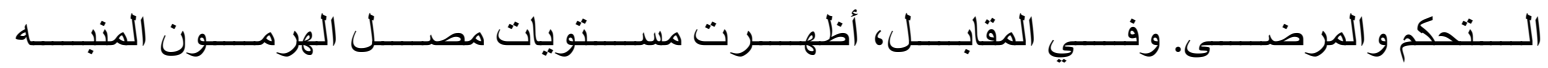

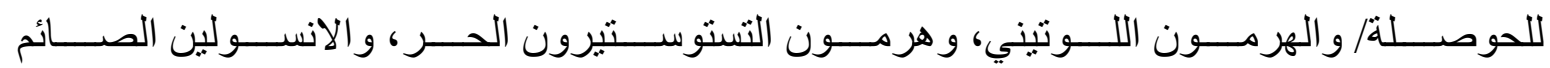

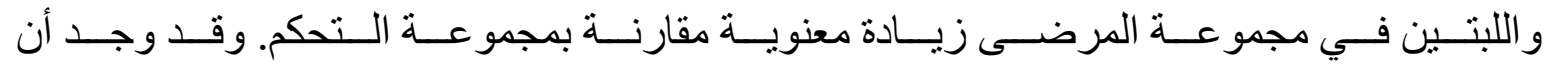

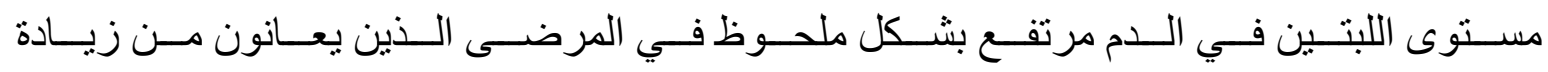

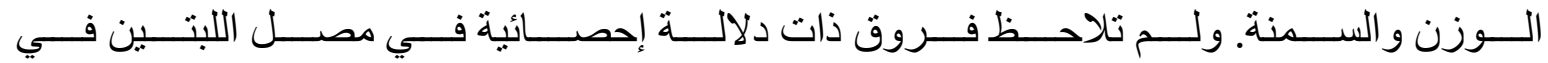

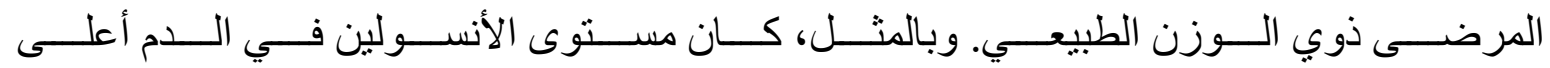




\section{ASHRAF FATHY MOHAMED $e t a l$,}

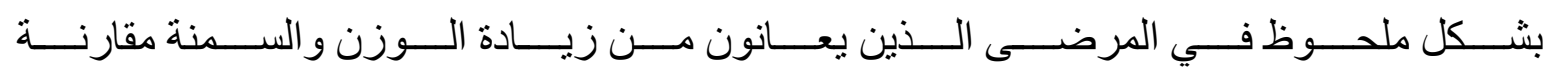

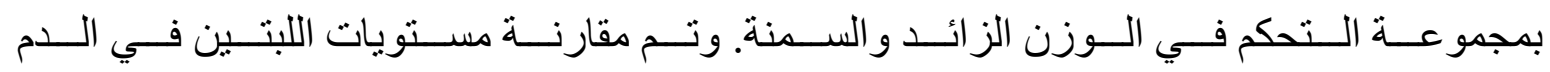

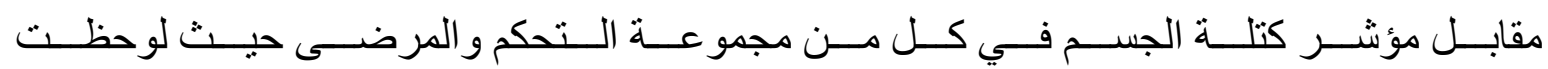

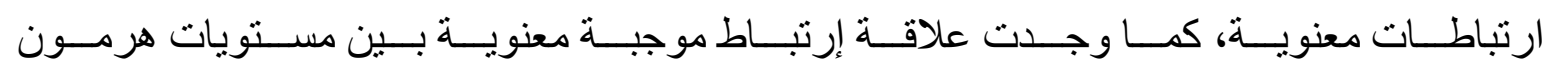
اللبتنين في الدم ومستويات الانسولين في الدام.

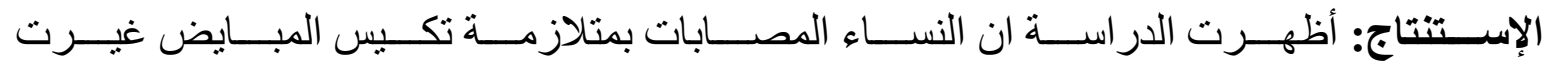

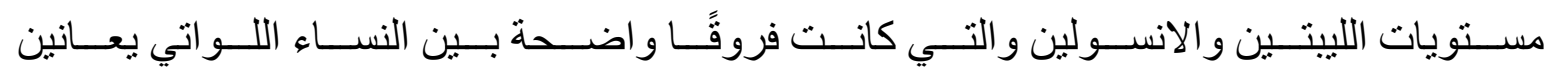

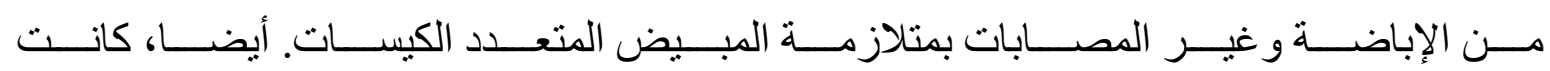

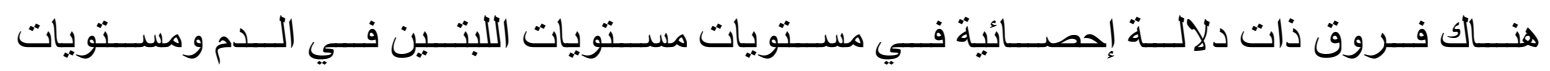

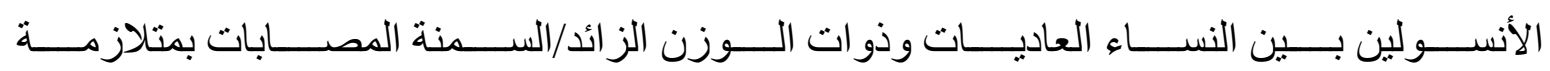

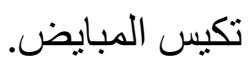

الكلمات الدالة: اللبتين، الانسولين، مؤشر كتلة الجسم، متلازمة تكيس المبايض. 